\title{
Economic emission dispatch for thermal power plant in Indonesia
}

\author{
Muhammad Bachtiar Nappu ${ }^{\mathrm{a}, \mathrm{b}, *}$, Ardiaty Arief $^{\mathrm{a}, \mathrm{b}}$ and Asnovita Sari Duhri ${ }^{\mathrm{a}, \mathrm{b}}$ \\ ${ }^{a}$ Centre for Research and Development on Energy and Electricity, Hasanuddin University, Makassar 90245, Indonesia \\ ${ }^{b}$ Electricity Market and Power Systems Research Group, Department of Electrical Engineering, Faculty of Engineering, \\ Hasanuddin University, Gowa 92119, Indonesia
}

\begin{abstract}
Industry in the power generation sector today has experienced a very significant development due to the increasing demand for electricity; hence an effort to optimize the generation of electricity is necessary. This study aims to optimize fuel costs and reduce the emissions of a gas and steam power plant in Indonesia, that is the Sengkang Power Plant. The method used is to conduct polynomial regression to find the functions of the fuel cost and the emission. To form an objective function of fuel cost with the consideration of emission, the weight sum method is used. With the newly acquired objective function, the Lagrange method is then employed to find the optimal point between the cost of electricity generation and the resulting NOx emissions. The optimization point of the generator is obtained by processing the operation data of the power plant in the form of peak load and base load that must be fulfilled by the plant on working days and public holidays and the NOx emissions generated at the same time. From the simulation results obtained, there are some combination of active power generation for 2 generator units that produce optimum operating costs with low emissions.
\end{abstract}

Keywords: active power, NOx emission, operation cost, sum weight method, Lagrange method.

\section{Introduction}

Currently, emission reductions are of concern to many parties in Indonesia. Indonesia's Second National Communication stated in 2005, that the total GHG emissions in Indonesia reached 1.1 Gton and the energy sector contributed 0.4 Gton or about $36 \%$ of the total greenhouse gas emissions [1]. Previously, electric power generation companies only focus on reducing plant operating costs to a minimum [2-4]. However, with the increasing attention of the Government of Indonesia and the society on the environment, there is a need to optimize the process of electric power generation that can meet the needs of the load but still take into account both the cost of fuel and emissions produced [5-7].

The Sengkang Gas and Steam Power Plant is the first IPP that provides electric power to the Southern Sulawesi interconnected power system in Indonesia for both the base and peak loads [8]. The Sengkang Power Plant consists of 2 blocks, i.e. block I and block II. The total power generated by the Sengkang Power Plant is $315 \mathrm{MW}$, where block I produces $135 \mathrm{MW}$ and block II produces $180 \mathrm{MW}$. Each block has 2 gas generator units and 1 steam generator unit which are used to cover the load requirement. The generator unit generating emissions from the combustion process is the gas generator unit. Therefore, the optimization is done only on the gas generator units that is the gas generators namely, GT 11 and GT 12.

\section{Economic and Emission Dispatch}

The problems of economic dispatch and emission dispatch can be solved by a combined economic and emission dispatch (CEED) that is oriented to economic and emissions priority with varied problems [9-

\footnotetext{
* Manuscript received September 4, 2018; revised May 9, 2019.

Corresponding author. E-mail address: thiar@engineer.com.

doi: 10.12720/sgce.8.4.500-504
} 
14]. Equations (1) and (2) inform the relationship between the fuel cost and the active power generated by the generator and the generated emission function, respectively [15].

$$
\begin{gathered}
C_{i}\left(P_{i}\right)=\alpha_{i}+\beta_{i} P_{i}+\gamma_{i} P_{i}^{2} \\
E_{i}\left(P_{i}\right)=\delta_{i}+\varepsilon_{i} P_{i}+\zeta_{i} P_{i}^{2}
\end{gathered}
$$

where,

$C_{i}\left(P_{i}\right) \quad$ is the operation cost of each generator unit (Rp/hour)

$P_{i} \quad$ is the power output of each generator unit (MW)

$\alpha_{i}, \beta_{\mathrm{i}}, \gamma_{i}$ are the generator's operation cost coefficients

$E_{i}\left(P_{i}\right)$ is the emission of each generator unit (ppmvd)

$\delta_{i}, \varepsilon_{i}, \zeta_{i}$ are the generator's emission coefficients

The simplest method to complete the optimization of multi objective functions such as the economic emission dispatch is by the weight sum method which combines two or more objective functions into a single unit, by the multiplication of each objective function with the weight coefficient of each objective function, whereby the total sum of each weight coefficient must be equal to one [16]. The weight coefficient should not be zero and the magnitude of the coefficient indicates the priority. Price penalty factor $(\rho)$ is used to form a new single objective function with the following equation [17], where price penalty factor is the ratio between the maximum fuel costs to the maximum emissions generated as shown in Eq. 5 [9].

$$
\begin{aligned}
& F_{T i}=\psi_{C} \cdot F C_{i}+\psi_{E} \cdot\left(\rho_{i} . F E_{i}\right) \\
& \psi_{C}+\psi_{E}=1 ; \quad \psi_{C} \neq 0 ; \quad \psi_{E} \neq 0 \\
& \rho_{i}=\frac{F C_{i}\left(P_{\text {iMax }}\right)}{F E_{i}\left(P_{\text {iMax }}\right)}
\end{aligned}
$$

Where,

$F_{T i}$ is the objective function

$F C_{i}$ is the $i^{\text {th }}$ generation cost

$F E_{i}$ is the emissions produced by the $i^{\text {th }}$ generator

$\rho_{i} \quad$ is the price penalty factor

$\psi_{C}$ is the weight cost of generator

$\psi_{E}$ is the weight emission of generator

To solve the problem of the objective function with unequal boundaries is by deriving the Lagrange function against each variable and it must be equal to zero [18]. The equation obtained from the partial derivative of the Lagrange function on the output power is formulated as follows [19]:

$$
\frac{\partial \mathcal{L}}{\partial P_{i}}=\frac{d F_{T i}}{d P_{i}}-\lambda=0
$$

\section{Results and Analysis}

\subsection{Fuel cost functions and emission functions}

Both the fuel cost function and NOx emission function of the case study are expressed by an objective function and generator inequality in the Cartesian diagram are shown in Fig. 1 and Fig. 2, respectively. 


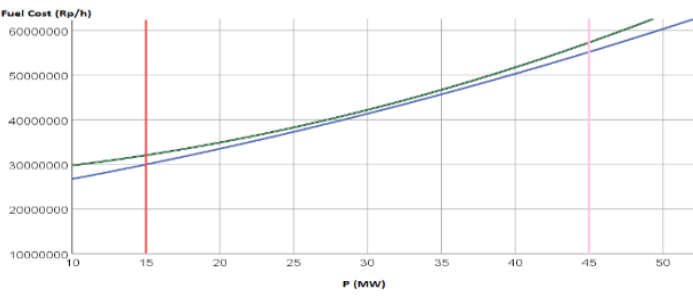

Fig. 1. Fuel cost functions for both generators

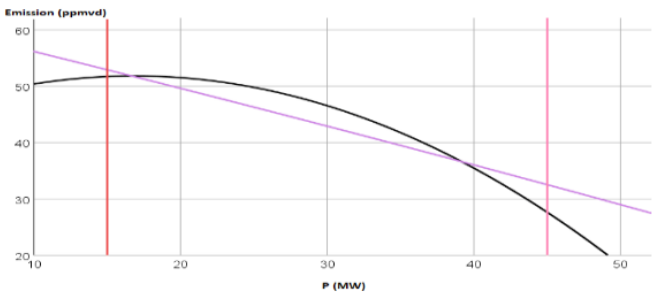

Fig. 2. Emission functions of NOx for both generators

\subsection{Economic emission dispatch optimization}

In optimizing fuel costs by considering economic and emission dispatch, it is necessary to change the optimization problem by creating a single objective function by using weight coefficient $(\psi)$ and price penalty factor $(\rho)$ as in Eq. 3. The price penalty factor compromises of the cost of emission and the cost of fuel. After determining the value of $\rho$, then the best weight $\psi$ coefficient needs to be determined to obtain a function with the optimum fuel and emission results. The first step to do with the Weight Sum Method (WSM) is to determine the criteria that will affect the alternative function in the calculation, then produce a new single objective function for each generation [20]. The coefficients of the new objective function for different alternatives are presented in Table 1 which follow the pattern in Eq. 7.

$$
\Phi_{i}\left(P_{i}\right)=\mu_{i}+v_{i} P_{i}+\varphi_{i} P_{i}^{2}
$$

Table 1. The coefficient of new objective function for generator 1 and 2

\begin{tabular}{lllllllll}
\hline \multirow{2}{*}{ Alternative } & \multirow{2}{*}{$\psi_{C}$} & $\psi_{E}$ & \multicolumn{2}{l}{$\Phi_{1}\left(P_{1}\right)$} & \multicolumn{3}{c}{$\Phi_{2}\left(P_{2}\right)$} \\
\cline { 4 - 8 } & & & $\mu_{1}$ & $v_{1}\left(P_{1}\right)$ & $\varphi_{1}\left(P_{1}\right)^{2}$ & $\mu_{2}$ & $v_{2}\left(P_{2}\right)$ & $\varphi_{2}\left(P_{2}\right)^{2}$ \\
\hline A1 & 0.50 & 0.50 & 58847168.331 & 77842.558 & -3015.957 & 58038300.823 & 1156549.808 & -26587.788 \\
A2 & 0.60 & 0.40 & 51282826.710 & 165354.349 & -1330.044 & 51795630.557 & 962132.802 & -19079.752 \\
A3 & 0.70 & 0.30 & 43718485.088 & 252866.141 & 355.8685 & 45552960.291 & 767715.796 & -11571.716 \\
A4 & 0.80 & 0.20 & 36154143.467 & 340377.932 & 2041.781 & 39310290.025 & 573298.790 & -4063.680 \\
A5 & 0.90 & 0.10 & 28589801.846 & 427889.723 & 3727.694 & 33067619.759 & 378881.784 & 3444.355 \\
A6 & 0.95 & 0.05 & 24807631.035 & 471645.618 & 4570.650 & 29946284.626 & 281673.281 & 7198.373 \\
A7 & 0.96 & 0.04 & 24051196.868 & 480396.793 & 4739.241 & 29322017.596 & 262231.581 & 7949.176 \\
A8 & 0.97 & 0.03 & 23294762.706 & 489147.972 & 4907.833 & 28697750.569 & 242789.880 & 8699.980 \\
A9 & 0.98 & 0.02 & 22538328.544 & 497899.151 & 5076.424 & 28073483.543 & 223348.180 & 9450.783 \\
A10 & 0.99 & 0.01 & 21781894.382 & 506650.330 & 5245.015 & 27449216.516 & 203906.479 & 10201.587 \\
\hline
\end{tabular}

It can be seen in Table 1 that after the weight method is performed to combine the functions of fuel cost and the emission into a new single objective function, only the alternatives A5-A10 produces all positive $\mu, v$ and $\varphi$ constants for the functions $\Phi_{1}\left(P_{1}\right)$ and $\Phi_{2}\left(P_{2}\right)$ that can form a positive polynomial function. The objective function characteristics that can be optimized to find the minimum value of fuel costs and emissions using the Lagrange method must be a positive polynomial function. Therefore functions A5-A10 are used to perform economic optimization of dispatch. The results of fuel cost optimization with the consideration of emissions can be seen in Fig. 3. The working day peak load is used in this simulation. 


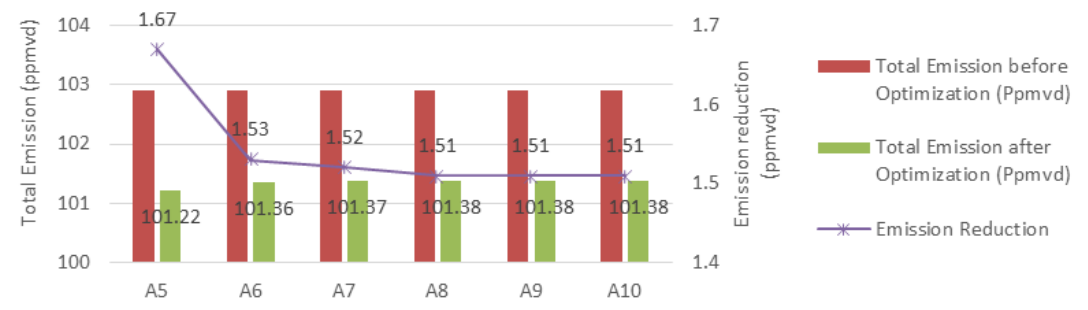

Fig. 3. Optimization results of fuel costs with emission considerations for different alternatives

As can be seen from Fig.3, the weight values of the $\psi_{C}$ and the $\psi_{E}$ shows the priority scale that will affect the generation cost and the amount of emissions generated. If the $\psi_{C}$ gets smaller and the $\psi_{E}$ gets bigger, the generation cost will be higher, but the resulting emission will be reduced. On the contrary if the $\psi_{C}$ is bigger and the $\psi_{E}$ is smaller, the generation cost will be smaller but the resulting emission will be increased. The emission prior to optimization was $102.89 \mathrm{ppmvd}$ or proportional to $193.580 \mu \mathrm{g} / \mathrm{m}^{3}$, which, if standardized, exceed the WHO standard, but is still within the Indonesian Ministry of Environment standards.

Based on the optimization results, alternative A5 with the $\psi_{C}$ of $90 \%$ and the $\psi_{E}$ of $10 \%$ produced the largest emissions savings compared to other alternatives, that is as much as $1.67 \mathrm{ppmvd}$, however it is the least economically, with the fuel cost amounting to $\mathrm{Rp} 83,341,500.094$. On the other hand, alternative A10 with the $\psi_{C}$ of $99 \%$ and the $\psi_{E}$ of $1 \%$ resulted in the most economical options from fuel cost perspectives but has the smallest emission reduction of only 1.51 ppmvd. Therefore with the A10 alternative, it gives the smallest operating fuel cost with a reduced emission and it is recommended for economic emission dispatch at Sengkang Power Plant.

Further research needs to be done for the economic emission dispatch in the Southern Sulawesi power system is the economic emission dispatch considering network losses and transmission congestion [2125]. In addition, study in reactive power compensating devices also important in optimizing the dispatch [26-28] as well as the stability studies [29-31].

\section{Conclusions}

This study performs economic emission dispatch for gas and steam power plant in Indonesia, that is the Sengkang power plant. By optimizing the economic emission dispatch, an optimal fuel cost that was obtained produces the less emission in the Sengkang power plant. Alternative A10 with the $\psi_{C}$ of $99 \%$ and the $\psi_{E}$ of $1 \%$ resulted in the cheapest fuel cost options but with emission reduction of only 1.51 ppmvd. Eventhough alternative A5 with the $\psi_{C}$ of $90 \%$ and the $\psi_{E}$ of $10 \%$ yielded the biggest emission saving compared to other alternatives but this option comes with significant large fuel cost, hence it is more recommended for applying the A10 alternative in the economic emission dispatch of the Sengkang power plant.

\section{Acknowledgements}

The authors gratefully acknowledge the Indonesian Ministry of Research, Technology and Higher Education for providing the research grant and support in this work and the Overseas Seminars Aid Program, Directorate General of Research Strengthening and Development, the Indonesian Ministry of Research, Technology and Higher Education for providing the travel grant.

\section{References}

[1] Kementerian Lingkungan Hidup (Indonesian Ministry of Environment), "Summary for Policy Makers: Indonesia Second National Communication Under the United Nations Framework Convention on Climate Change (UNFCCC)," Unit Asdep 
Pengendalian Dampak Perubahan Iklim Kementerian Negara Lingkungan Hidup, Ed., ed. Jakarta, 2009.

[2] $\mathrm{Li} \mathrm{P}$ and $\mathrm{Hu}$ J. An ADMM based distributed finite-time algorithm for economic dispatch problems. IEEE Access, vol. 6, pp. 30969-30976, 2018.

[3] Choi J. et al., "Economic dispatch of multiple energy storage systems under different characteristics," Energy Procedia, vol. 141, pp. 216-221, 2017/12/01/ 2017.

[4] Azis F. et al., Fuzzy logic based active power generation dispatching considering intermittent wind power plants output. in Proc. 2017 International Conference on Control, Electronics, Renewable Energy and Communications (ICCREC), 2017, pp. 116-121.

[5] Mahdi FP. et al., A holistic review on optimization strategies for combined economic emission dispatch problem. Renewable and Sustainable Energy Reviews, 81; 3006-3020, 2018/01/01/ 2018.

[6] Shaabani YA. et al., Stochastic multi-objective optimization of combined heat and power economic/emission dispatch. Energy, 141; 1892-1904, 2017/12/15/ 2017.

[7] Ghorbani N. et al., Exchange market algorithm for multi-objective economic emission dispatch and reliability. Procedia Computer Science, 120; 633-640, 2017/01/01/ 2017.

[8] Energi Sengkang PT. (1 July). The Sengkang Power Project. Available: http://www.cepa.co.id/index.php/the-sengkangpower-project

[9] Venkatesh P. et al., Comparison and application of evolutionary programming techniques to combined economic emission dispatch with line flow constraints. IEEE Transactions on Power Systems, 18; 688-697, 2003.

[10] Liang H. et al., "A multiobjective hybrid bat algorithm for combined economic/emission dispatch," International Journal of Electrical Power \& Energy Systems, vol. 101, pp. 103-115, 2018/10/01/ 2018.

[11] Secui DC. Large-scale multi-area economic/emission dispatch based on a new symbiotic organisms search algorithm. Energy Conversion and Management, 154; 203-223, 2017/12/15/ 2017.

[12] Mason K. et al., A multi-objective neural network trained with differential evolution for dynamic economic emission dispatch. International Journal of Electrical Power \& Energy Systems, 100: 201-221, 2018/09/01/ 2018.

[13] Andervazh MR and Javadi S. Emission-economic dispatch of thermal power generation units in the presence of hybrid electric vehicles and correlated wind power plants. IET Generation, Transmission \& Distribution, vol. 11, pp. 2232-2243, 2017.

[14] Khan NA et al., Optimizing combined emission economic dispatch for solar integrated power systems. IEEE Access, 4: 3340-3348, 2016.

[15] Kuo MT. et al., Considering carbon emissions in economic dispatch planning for isolated power systems: a case study of the taiwan power system. IEEE Transactions on Industry Applications, 54; 987-997, 2018.

[16] Narimani H. et al., "A multi-objective framework for multi-area economic emission dispatch," Energy, 154: 126-142, 2018/07/01/ 2018.

[17] Gupta A. et al., Combined economic emission dispatch problem of thermal generating units using particle swarm optimization. International Journal of Scientific and Research Publications, 2; 1 - 7, 2012.

[18] Meng W. and Wang X. Distributed energy management in smart grid with wind power and temporally coupled constraints. IEEE Transactions on Industrial Electronics, 64; 6052-6062, 2017.

[19] Wood AJ and Wollenberg BF, Power Generation, Operation and Control: New York: John Wiley \& Sons, Inc, 1996.

[20] Abdullah MN, et al. Modified particle swarm optimization for economic-emission load dispatch of power system operation. Turkish Journal of Electrical Engineering \& Computer Sciences, 2015; 23: 2304 - 2318.

[21] Nappu MB. et al., Network losses reduction due to new hydro power plant integration. in Proc. 2016 3rd International Conference on Information Technology, Computer, and Electrical Engineering (ICITACEE), 2016; 181-185.

[22] Nappu MB and Arief A. Network losses-based economic redispatch for optimal energy pricing in a congested power system. Energy Procedia, ELSEVIER, September, pp. 311-314, 2016.

[23] Nappu MB and Arief A. Economic redispatch considering transmission congestion for optimal energy price in a deregulated power system. in 2015 International Conference on Electrical Engineering and Informatics (ICEEI), 2015, pp. 573-578.

[24] Nappu MB, et al., Transmission management for congested power system: A review of concepts, technical challenges and development of a new methodology. Renewable and Sustainable Energy Reviews, ELSEVIER, 38; 572-580, 2014.

[25] Nappu MB, et al., Market power implication on congested power system: A case study of financial withheld strategy. International Journal of Electrical Power \& Energy Systems, ELSEVIER, 47; 408-415, 2013.

[26] Arief A, et al., Analytical method for reactive power compensators allocation. International Journal of Technology, 2018; $9(3) ; 602-612$

[27] Arief A, et al., An analytical method for optimal capacitors placement from the inversed reduced jacobian matrix. Energy Procedia, ELSEVIER, September, 307-310, 2016.

[28] Mustafa S. et al., Optimal capacitor placement and economic analysis for reactive power compensation to improve system's efficiency at Bosowa Cement Industry, Maros. in Proc. 2018 International Conference on Information and Communications Technology (ICOIACT), 2018, pp. 778-783.

[29] Arief A and Nappu MB. Voltage drop simulation at Southern Sulawesi power system considering composite load model in 2016 3rd International Conference on Information Technology, Computer, and Electrical Engineering (ICITACEE), 2016, pp. 169-172.

[30] Arief A. et al., Under voltage load shedding in power systems with wind turbine-driven doubly fed induction generators. Electric Power Systems Research, ELSEVIER, 96; 91-100, 2013.

[31] Utomo BT, et al., The Placement of the Transmission Lightning Arrester (TLA) at $150 \mathrm{kV}$ Network using Fuzzy Logic. presented at the 10th The International Conference on Information Technology and Electrical Engineering (ICITEE), Bali, Indonesia, 24-26 July, 2018. 